Mental health is a core part of the Sustainable Development Goals (SDGs) agreed by the United Nations General Assembly. This follows on from the World Health Organization's 2013 Global Action Programme. The World Bank is also expected to give mental health greater priority. Moreover, mental health is now seen as essential in disaster relief management. However, although global policy towards mental health has improved, there are only rare examples where this has been translated at scale into action. There are, nonetheless, reasons for optimism in the new policy background, in the many innovative practical developments around the world and in the way that evidence is being gathered and learning shared. The understanding that mental health is intimately connected to physical, social, environmental and economic health - which is so evident in the SDGs - represents a major change in mind-sets globally.

Mental health has gained much greater priority globally since 2000, when the Millennium Development Goals (MDGs) made no mention of mental health (World Health Organization, 2015). Today, mental health is a core part of the Sustainable Development Goals (SDGs) agreed by the United Nations General Assembly in September 2015 as the successors to the MDGs. This follows on from the World Health Organization's Global Action Programme agreed at the World Health Assembly in 2013. All being well, the World Bank will also give mental health greater priority following its April 2016 summit on depression. Moreover, mental health is now seen as essential in disaster relief management and other global policies (United Nations Office for Disaster Risk Reduction, 2015).

The SDGs set out 17 goals for the world's development agenda to 2030 , with goal 3 reading 'Ensure healthy lives and promote well-being for all at all ages'. Two of the 13 targets which make up this goal are specifically about mental health and substance misuse. In addition, the preamble to the declaration on the SDGs makes it clear that mental health is both included in the definition of non-communicable diseases and is a core element of universal health coverage. As importantly, the whole of that declaration is suffused with a clear understanding of the connections between all the goals, whether they are about economic development, the environment or social issues. It places health firmly within these wider determinants: in effect recognising the full biopsychosocial nature of health and well-being. Additionally, the SDGs, unlike the MDGs, are universal and apply to all countries in the world - they are not just about the development of the poorest. We are in this together and we need to develop together, learn together and tackle common problems together.

These global policy gains are of fundamental importance and very much worth celebrating; however, a cynic might point out that mental health is still only part of one-seventeenth of the highly aspirational SDGs. Moreover, we have yet to see whether this priority in these high-level plans will be translated through into a priority at national level. The struggle to improve mental health and gain access to mental health services for the millions who need them has been immense over the past half century. Over this period, many people and organisations have worked intensively in low- and middle-income countries to establish training programmes, to decentralise services and to integrate mental health into primary care - including the Mental Health Division of the World Health Organization, the World Federation of Mental Health, professional bodies such as the World Psychiatric Association, and many individuals. We are, nevertheless, at best only at the end of the beginning of the struggle to improve both mental health and access to services.

The gap between what is needed and current funding and provision is enormous. The problem is clearly illustrated in Fig. 1, which compares the percentage of total health spending that goes on mental health with the burden of diseases for all mental health and neurological conditions. It shows that there are major problems in all countries but that the gap between need and funding is greatest in the poorest countries.

\section{Turning global policy commitments into local action}

The translation of these global policy commitments into local action is fraught with difficulty. It requires:

- the policy commitment and political will globally, nationally and locally to make improvements

- practical and evidence-based ideas and methods for doing this successfully

- the mobilisation of resources and implementation of plans.

Continuing advocacy will be needed to strengthen policies and build the political will at 


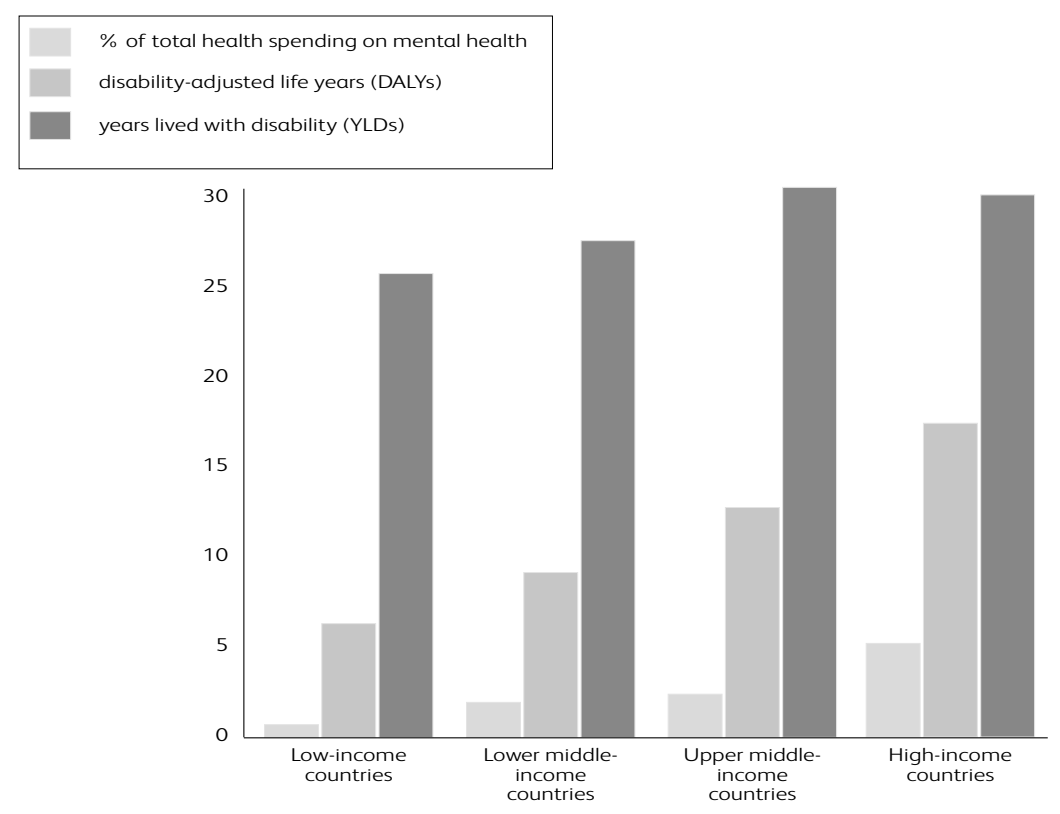

Fig. 1

Percentage of total health spending that is spent on mental health compared with the burden of diseases (DALYs and YLDs) for all mental health and neurological conditions. Reproduced from Patel et al (2013)

all levels to make improvements. Moreover, the job will never be finished. It is instructive to note that the advocates for HIV/AIDS who helped build the massive global political will to tackle the epidemic from the 1980s onwards still need to be active today in an environment where some see HIV/ AIDS as yesterday's problem.

Mental health is, of course, only at the beginning of this process, with many political leaders and policy makers around the world still seemingly

\section{Box 1. The health, social and economic, and human rights cases for investing in mental health}

\section{The health case}

People with mental health problems have shorter lives and worse health than others. This is due to suicide, mental health problems worsening the course of physical health problems and interfering with appropriate care and selfmanagement, and poorer treatment of those problems by the health system.

\section{The social and economic case}

Mental health problems are a brake on development as they cause (and are caused by) poverty. This fuels social failures, including poor parenting and school failure, domestic violence and toxic stress, preventing people with problems and their families from earning a living.

\section{The human rights case}

People with mental health problems are often subjected to serious abuse, such as chaining, and in many countries are denied fundamental human rights and protections.

Source: All-Party Parliamentary Group on Global Health (2014, p. 5).

needing to be convinced of the 'compelling' case made by Thornicroft \& Patel (2014) and by what the All-Party Parliamentary Group on Global Health (2014) called the health, social and economic, and human rights cases for action on mental health, summarised in Box 1, which illustrates how essential improved mental health is for sustainable development.

Mental health organisations around the world have a strong history of coming together to promote consistent messages, for example with World Mental Health Day celebrated every year since 1992, advocacy for mental health to be included in the recent United Nations initiative on non-communicable diseases, and recently with an initiative called FundaMentalSGD established to lobby for mental health in the SDGs. This consistency of message needs to be maintained. Moreover, it is essential to align the policies of all the global players: the United Nations, the World Health Organization, the World Bank and others. Part of the unfinished advocacy of the SDGs is to ensure that the two indicators which will be used to monitor implementation of their mental health elements are the same as, or at least closely related to, those in the World Health Organization's Global Action Programme, namely that:

- service coverage for severe mental disorders will have increased by $20 \%$ by 2020 ;

- the rate of suicide will be reduced by $10 \%$ by 2020.

It will be difficult in many countries to collect these data adequately. Therefore attention needs to be paid to strengthening health information management systems and, where necessary, finding appropriate related indicators.

Part of successful advocacy is being able to demonstrate what works - both clinically and organisationally - and how this can be applied to a local context. The Mental Health Innovation Network (http://www.mhinnovation.net) now has 120 mental health research programmes and projects on its database and has begun to play a crucial role in sharing the learning from researchbased practical projects globally and in creating a community of practitioners and researchers who can develop new ideas together.

Three practical themes are very important in these developments:

- There is a need to link mental and physical health, with an emphasis on integrating mental health into primary care - recognising the important relationships between the two but also that people with mental health problems very often miss out on physical health services, have more illnesses and die much younger (Jenkins et al, 2010).

- Chronic disease models should be used for mental health - now that it is accepted that mental illnesses are part of the global agenda on non-communicable diseases - as well as acute service models. 
- There is a need, as part of this, both to develop new sorts of health workers within mental health and to provide education for health workers generally to ensure that they can all undertake psychosocial-physical assessments of their patients and deliver services accordingly.

\section{Implementation - the crucial next step}

Policy and research-based evidence of what works need to be followed by successful implementation. As De Silva \& Ryan (2016) argue, 'the rise of implementation science is the crucial next step in the evolution of global mental health'. They point, for example, to the important work being done by PRIME (a UK-funded consortium working on district-level mental health plans) and EMERALD (with its focus on national policy and system-level issues) in India, Nepal, Uganda, South Africa, Ethiopia and Nigeria. Between them these two projects are learning how best to implement improvement in these very different environments.

Knowledge about implementation needs also to be accompanied by resources. Middle-income countries should expect to fund developments themselves - as with all the SDGs; low-income countries, however, will need to rely on development partners. A recent study shows that while development assistance for mental health increased between 2007 and 2013, it remains low in absolute terms and amounts to no more than $1 \%$ of total development assistance (Gilbert et al, 2015).

\section{Reasons for concern and optimism}

There are real reasons for concern for the future. Global policy towards mental health has improved but there are only rare examples as yet where this has been translated at scale into action and resourcing. There are, however, substantial reasons for optimism in the new policy background, in the many innovative practical developments around the world and in the way that evidence is being gathered and learning shared. Perhaps most importantly, the understanding that mental health is intimately connected to physical, social, environmental and economic health - which is so evident in the SDGs - represents a major and very hopeful change in mind-sets globally.

\section{References}

All-Party Parliamentary Group on Global Health (2014) Mental Health for Sustainable Development. All-Party Parliamentary Group on Global Health.

De Silva, M. J. \& Ryan, G. (2016) Global mental health in 2015: $95 \%$ implementation. Lancet Psychiatry, 3, 15-16.

Gilbert, B. J., Patel, V., Farmer, P. E., et al (2015) Assessing development assistance for mental health in developing countries: 2007-2013. PLoS Med, 12(6), e1001834 (doi:10.1371/journal. pmed.1001834).

Jenkins, R., Kiima, D., Okonji, M., et al (2010) Integration of mental health in primary care and community health working in Kenya: context, rationale, coverage and sustainability. Mental Health in Family Medicine, 7, 37-47.

Patel, V., Saxana, S., De Silva, M., et al (2013) Transforming Lives, Enhancing Communities: Innovations in Mental Health. World Innovation Summit in Health.

Thornicroft, G. \& Patel, V. (2014) Including mental health among the new sustainable development goals. The case is compelling. $B M J, 349$, g5189.

United Nations General Assembly (2015) Resolution 70/1: Transforming our World: the 2030 Agenda for Sustainable Development. United Nations. Available at http://www.un.org/ga/ search/view_doc.asp?symbol=A/RES/70/1\&Lang=E (accessed 9 January 2016).

United Nations Office for Disaster Risk Reduction (2015) Sendai Framework for Disaster Risk Reduction 2015-2030. UNISDR. Available at http://www.unisdr.org/we/inform/publications/43291 (accessed 10 January 2016)

World Health Organization (2013) World Health Assembly Resolution 66/8: Comprehensive Mental Health Action Plan 2013-2020. Available at http://apps.who.int/gb/ebwha/pdf_files/ WHA66/A66_R8-en.pdf?ua=1 (accessed 10 January 2016).

World Health Organization (2015) Health in 2015: From MDGs to SDGs. WHO. Available at http://www.who.int/gho/publications/ mdgs-sdgs/en/ (accessed 9 January 2016).

\section{THEMATIC} PAPER

\title{
Mental health services for asylum seekers and refugees: a snapshot
}

\author{
Katy Briffa
}

Consultant General Adult Psychiatrist for the Asylum Seeker and Refugee Mental Health Service, Livewell Southwest, Plymouth, UK, email Katy.briffa@ nhs.net
As fellow human beings uproot their lives in search of protection, and for those who survive to reach European shores, many countries are faced with an unprecedented, highly complex challenge of managing huge and immediate need. Clearly, immigration agencies are front line in this scenario, but they are closely followed by accommodation, subsistence, community and health agencies. It is widely recognised that the mental health burden of asylum seekers is large and the stir of growing interest at a clinical level in addressing that burden is encouraging. Mental health services have been aware of asylum seekers and refugees for decades but we have grappled with our role, been confused by the relevance of a political dimension and overwhelmed with how to manage diverse need, in the face of endless competing demands. Mental health services for asylum seekers and refugees have 